\section{Hyperuricemia and carotid artery dilatation among young adults without metabolic syndrome}

\author{
Eswar Krishnan, ${ }^{1}$ Rachel P. Wildman, ${ }^{2}$ \\ Emma Barinas-Mitchell, ${ }^{3}$ Jennifer \\ Cooper, ${ }^{3}$ Kim Sutton-Tyrrell ${ }^{3}$ \\ 1Department of Medicine, Stanford \\ University School of Medicine, CA; \\ 2Department of Epidemiology and \\ Population Health, Albert Einstein \\ College of Medicine, NY; ${ }^{3}$ Department \\ of Epidemiology, School of Public Health, \\ University of Pittsburgh, PA, USA
}

\section{Abstract}

It is not known if hyperuricemia is associated with early vascular changes signifying arteriosclerosis. We performed a cross sectional study of 163 young adults without metabolic syndrome in Allegheny County, PA, USA. Doppler ultrasound was used to measure two metrics of early arteriosclerosis: carotid artery dimensions and aortic pulse wave velocity. Individuals in the highest quartiles of serum uric acid ( $>6.2 \mathrm{mg} / \mathrm{dL}$ for men and $>4.6$ for women) were more likely to be of younger age, and to possess greater measures of adiposity and an adverse cardiovascular risk profile. Higher serum uric acid concentration was associated with larger luminal and adventitial diameters as well as changes in diameters between the phases of the cardiac cycle $(\mathrm{P}<0.001)$ but not with carotid intima media thickness, pulse wave velocity, or pressure strain modulus. In multivariable linear regression models where the effects of age, ethnicity, serum creatinine, systolic blood pressure, current alcohol use, body mass index and smoking status were accounted for, the highest quartile of serum uric acid was associated with greater luminal and adventitial diameters and change in luminal diameter between the phases of cardiac cycle $(\mathrm{P}<0.05)$, but not with pulse wave velocity, pressure strain modulus or carotid intima media thickness. We can conclude that hyperuricemia is associated with larger carotid artery diameters signifying an early adaptive response to vascular stress. This has implications on the observed link between hyperuricemia and hypertension.

\section{Introduction}

Numerous epidemiological studies have reported that hyperuricemia is a risk factor for hypertension suggesting a causal role. ${ }^{1-4}$ Uric acid induces vascular smooth muscle cell proliferation and in rat models of hypertension, treatment with allopurinol has a beneficial effect on vascular remodeling. ${ }^{5}$ On the other hand, skeptics argue that these observations merely reflect confounding by various comorbid conditions such as insulin resistance and subclinical renal disease. ${ }^{6}$ If the link between hyperuricemia and hypertension is indeed causal, one would be able to document that hyperuricemia is associated with morphological and functional consequences of subclinical vascular disease, independent of other risk factors. Previous studies that addressed this question included relatively older subjects who had hypertension and/or metabolic syndrome. ${ }^{7-11}$ Thus the relationship between abnormal carotid measures and uric acid has not been very clear and has been understudied in younger populations. We theorize that if the uric acid-atherosclerosis link were real, early vascular changes will be evident in young individuals who do not have hypertension and metabolic syndrome. In this study we tested the hypothesis that hyperuricemia is associated with carotid artery changes suggesting early vascular disease in a community-drawn sample of non-diseased young adult volunteers in Allegheny county, Pennsylvania, USA.

\section{Materials and Methods}

\section{Study design and subjects}

This study utilized a subset of the baseline data from a 2 year longitudinal observational study based at the Graduate School of Public Health, University of Pittsburgh. The institutional review board of the University of Pittsburgh approved this study. Individuals aged 20-40 years, of either sex or any race-ethnic category residing in Allegheny county PA were invited to be a part of this study by means of newspaper advertisements, mailed flyers, and automatic voice messages through the University of Pittsburgh voice mail messaging system. The exclusion criteria applied for this study were: i) history of any cardiovascular disease or systemic lupus erythematosus; ii) use of cardiovascular medications (anti diabetic, antihypertensive, antilipemic) and iii) thyroid related medications. Of the 207 individuals enrolled in the study, additional exclusions were performed for the presence of ATPIII defined metabolic syndrome, ${ }^{12}$ and for missing data on either uric acid or vascular measures, leaving 163 individuals for the present analyses.

\section{Clinical and laboratory measures}

Age, history of smoking (defined as ever-
Correspondence: Eswar Krishnan, Department of Medicine, Stanford University School of Medicine 1000 Welch Road, Suite 203, Palo Alto CA 94304, USA.

Tel. +1.650.7258004 - Fax: +1.518.7239651

E-mail: e.krishnan@stanford.edu

Key words: uric acid, carotid artery, ultrasound, adaptation.

Acknowledgements: Dr Krishnan has received unrestricted grants from Takeda Pharmaceuticals International, Inc. He also has served as an advisor and consultant for Takeda as well as Savient Pharmaceuticals in the past for other research projects. Other authors have nothing to disclose.

Conflict of interests: the authors report no potential conflict of interests.

Received for publication: 2 August 2011.

Revision received: 1 May 2012.

Accepted for publication: 15 May 2012

This work is licensed under a Creative Commons Attribution NonCommercial 3.0 License (CC BYNC 3.0).

(C) Copyright E. Krishnan et al., 2012

Licensee PAGEPress, Italy

Rheumatology Reports 2012; 4:e7

doi:10.4081/rr.2012.e7

versus never-smoking), and highest education level achieved were assessed by questionnaire. Physical activity was measured by Godin score of leisure-time activity questionnaire. ${ }^{13}$ In addition to supine blood pressure measurements, 3 consecutive, seated, heart rate and blood pressure measurements were taken at the ultrasound examination, after 5 minutes of rest, with a standard mercury sphygmomanometer and cuff sizes according to the manufacturer's recommendations. Staff members who performed the seated blood pressure measurements had been certified by a standard clinic protocol. The first measurement was discarded, and the second and third measurements were averaged. Seated blood pressure variables included systolic (SBP) and diastolic blood pressure (DBP), pulse pressure (PP, calculated as SBP-DBP), and mean arterial pressure [MAP, calculated as $\mathrm{DBP}+1 / 3$ (PP)]. Two measurements of weight, waist circumference, and hip circumference were assessed with a standard scale or tape measure and averaged. Body mass index was calculated by dividing the participant's weight in kilograms by the square of his/her height in meters (measured with a standard stadiometer). Total cholesterol, HDL cholesterol, LDL cholesterol, triglyceride, uric acid, serum creatinine and glucose values were determined after a 12-hour fast by standard laboratory procedures. Glomerular filtration rate was esti- 
mated using Modification of Diet in Renal Disease equation. ${ }^{14}$

\section{Ultrasound measures and quality control}

In this study we have used three broad categories of vascular measures. The first was the aortic pulse wave velocity (aPWV), an indirect measure of vascular stiffness. Next were arterial diameters measured during systole and diastole, as well as the change in arterial diameters across the cardiac cycle. The last measure we used was the anatomical measure of carotid vessel wall - intima-media thickness (IMT). All vascular studies were performed at the Ultrasound Research Laboratory of the University of Pittsburgh Graduate School of Public Health by trained technologists using standardized protocols. We have reported previously that vascular measurements performed at this laboratory, such as carotid IMT, aPWV, and plaques have excellent reproducibility. ${ }^{15-17}$

\section{Measures of vascular stiffness}

Using non-directional transcutaneous Doppler flow probes (model 810-a, $10 \mathrm{MHz}$; Parks Medical Electronics, Aloha, OR), simultaneous Doppler flow signals were obtained at right carotid and right femoral arteries after $\sim 30$ min of supine rest. ${ }^{15}$ The distance between the carotid and femoral sites was measured using a metal tape measure. Distance was calculated as carotid-femoral distance $=[$ (suprasternal-umbilicus $)+($ umbilicus-femoral) ] - (carotid-suprasternal). Three runs were performed for each participant, and the mean of waveforms from all usable runs was used in analyses. Data were scored using software developed by the Laboratory of Cardiovascular Science, Gerontology Research Center, National Institute on Aging, which averages the waveforms and determines the time from the R-wave to the foot of each waveform. The aPWV was calculated as the carotidfemoral distance divided by the time interval between carotid and femoral waveforms. A higher aPWV indicates stiffer vessels.

\section{Carotid intima-media thickness and diameters}

Carotid IMT was assessed by duplex scanning using a Toshiba SSA-270A scanner. Images were taken from the near and far walls of the distal common carotid artery (one centimeter proximal to the carotid bulb), the carotid bulb (the point at which the near and far walls of the common carotid artery were no longer parallel to the tip of the flow divider), and the first $1 \mathrm{~cm}$ of the internal carotid artery (from the tip of the flow divider). Intimalmedial thickening measures were obtained by electronically tracing the lumen-intima interface and the media-adventitia interface across these segments; one measurement was generated for each pixel over the area, for a total of approximately 140 measures for each segment. The average, standard deviation, minimum and maximum values for these measures were recorded for all 8 locations. For analyses, the mean value of the average readings and that of the maximum readings at all 8 locations were used. For common carotid artery measurements, the left distal common carotid artery near and far walls were imaged, and lines were electronically drawn along a $1 \mathrm{~cm}$ segment of the lumen-intima interface and the mediaadventitia interface. The lumen diameter (intima-intima distance) was calculated directly from the imaged interfaces. Common carotid inter-adventitial diameter was calculated by the following equation: lumen diameter plus near wall thickness plus far wall thickness. Change in lumen diameter was calculated as percent change in diameter between systole and diastole.

Pressure strain modulus was defined as the pressure needed to increase the lumen diameter by $1 \%$, with higher values reflecting stiffer vessels. This was calculated by the following formula:

\section{Pressure strain modulus $=\quad \frac{\Delta p}{\Delta d}$ $\frac{\Delta d}{D}$}

where $\Delta \mathrm{p}$ is the pulse pressure recorded at the brachial artery, $\Delta \mathrm{d}$ is the difference between systolic and diastolic carotid artery lumen diameters and D is the average of these two diameters. ${ }^{18}$

\section{Statistical analyses}

All analyses were performed using STATA 9SE ${ }^{\circledR}$ (College Station TX, USA). The vascular measures were normally distributed. We used ordinary least squared regressions to study the relationships between serum uric acid measurements and ultrasonographic measures, with and without adjustment for potential confounders. These potential confounders were age, gender, race, body mass index, serum creatinine and systolic blood pressure.

\section{Results}

Table 1 shows the characteristics of the 163 study participants. Participants with higher levels of serum uric acid were more likely to be male, of younger age, and to have larger body dimensions and an adverse cardiovascular risk profile. However, there were no significant differences among the increasing strata of serum uric acid in terms of measures of renal function, physical activity score, and total cholesterol. Carotid artery dimensions and hemodynamic measures by strata of serum uric acid are shown in Table 2. Notably, higher levels of serum uric acid were associated with greater carotid artery luminal and adventitial diameters. There were no differences in other vascular measures by serum uric acid quartile.

Table 3 presents the results for multivariate linear regressions for assessing serum uric acid as an independent correlate of each of the vascular measures. In these regressions, increasing serum uric acid was associated with larger luminal and adventitial diameters but not pulse wave velocity, pressure strain modulus or intima media thickness.

Serum uric acid is known to vary systematically between races and genders and with increasing age. We performed tests for two way interactions between sex, race, age categories $(<30 / \geq 30$ years) and uric acid and found no interactions.

\section{Discussion}

The current study demonstrates that higher uric acid levels are associated with larger carotid artery diameters in young adults at low risk of carotid artery dilatation. The change in diameter with phases of the cardiac cycle was lesser among those with higher concentrations of serum uric acid suggesting an early impairment. Hyperuricemia was not associated with other measures of vascular health such as aPWV and pressure strain modulus. These findings provide clues about the pathophysiological pathways that link hyperuricemia and vascular disease.

Larger luminal and adventitial carotid artery diameters are associated with adverse cardiovascular risk factor levels in young and middleaged adults, ${ }^{19-21}$ and are also associated with an increased risk of coronary heart disease. In the Atherosclerosis Risk in Communities Study population, increased adventitial diameter was associated with prevalent coronary heart disease and incident cardiac events in both men and women, and the associations remained significant after adjustment for cardiovascular risk factors. ${ }^{22}$ In the Rotterdam study, after adjustment for carotid IMT and cardiovascular risk factors, each SD higher baseline lumen diameter was associated with an $11 \%$ increase in risk of myocardial infarction. ${ }^{23}$ Arteries that are highly dilated have a decreased capacity to enlarge in response to a stimulus, which may leave the arteries more vulnerable to damage from heightened risk factor levels and more susceptible to atherosclerosis progression.

Arteriosclerosis is a condition that is manifested by hardening of arteries and is often associated with, and precedes hypertension. Ultrasonography enables sophisticated evaluation of the function and structure of the carotid artery and provides critical insight into early changes that precede hypertension. 
Table 1. Baseline characteristics of the study participants $(n=163)$.

\begin{tabular}{|c|c|c|c|c|c|c|c|c|c|}
\hline \multirow{5}{*}{$\begin{array}{l} \\
\text { Men } \\
\text { Women } \\
\text { Age in years }\end{array}$} & \multicolumn{8}{|c|}{ Baseline serum uric acid } & \multirow{4}{*}{$\begin{array}{l}\text { Trend } \\
\text { Test P } \\
\text { value* }\end{array}$} \\
\hline & \multirow{3}{*}{\multicolumn{2}{|c|}{$\begin{array}{l}\text { Quartile } 1 \\
\qquad \begin{array}{l}<4.9 \\
<3.6\end{array}\end{array}$}} & \multirow{3}{*}{\multicolumn{2}{|c|}{$\begin{array}{l}\text { Quartile } 2 \\
4.9-5.6 \\
3.6-4.2\end{array}$}} & \multirow{3}{*}{\multicolumn{2}{|c|}{$\begin{array}{c}\text { Quartile } 3 \\
\begin{array}{l}5.7-6.2 \\
4.2-4.6\end{array}\end{array}$}} & \multirow{3}{*}{\multicolumn{2}{|c|}{$\begin{array}{l}\text { Quartile } 4 \\
\qquad \begin{array}{l}>6.2 \\
>4.6\end{array}\end{array}$}} & \\
\hline & & & & & & & & & \\
\hline & & & & & & & & & \\
\hline & 31 & $(6)$ & 32 & $(6)$ & 28 & $(6)$ & 29 & $(6)$ & $0.03^{* *}$ \\
\hline Proportion of men (\%) & 49.1 & & 48 & & 47 & & 50 & & 0.9 \\
\hline Proportion of Caucasians (\%) & 47.1 & & 56.1 & & 52.1 & & 44.1 & & 0.10 \\
\hline Weight (kg) & 71 & (12) & 73 & (15) & 76 & (17) & 91 & (19) & $<0.001$ \\
\hline Height $(\mathrm{cm})$ & 169 & (8) & 170 & (9) & 170 & (9) & 172 & (10) & 0.008 \\
\hline Body mass index $\left(\mathrm{kg} / \mathrm{gm}^{2}\right)$ & 25 & (4) & 25 & (4) & 26 & $(6)$ & 31 & $(6)$ & $<0.001$ \\
\hline Waist circumference $(\mathrm{cm})$ & 77 & (9) & 79 & (11) & 81 & (12) & 93 & (14) & $<0.001$ \\
\hline Hip circumference $(\mathrm{cm})$ & 98 & (8) & 99 & $(9)$ & 101 & (10) & 108 & $(12)$ & $<0.001$ \\
\hline Systolic blood pressure (mm Hg) & 107 & (8) & 108 & (9) & 107 & (10) & 111 & (12) & $<0.01$ \\
\hline Diastolic blood pressure (mm Hg) & 67 & (8) & 70 & (7) & 68 & (9) & 69 & (8) & 0.14 \\
\hline Mean arterial pressure (mm HG) & 80 & (8) & 82 & (7) & 81 & (9) & 83 & (9) & 0.04 \\
\hline Pulse pressure (mm Hg) & 39 & (5) & 38 & (7) & 39 & (7) & 41 & $(10)$ & 0.25 \\
\hline Fasting glucose (mg/dL) & 78 & (7) & 79 & $(60$ & 78 & (7) & 81 & (6) & 0.01 \\
\hline Total cholesterol (mg/dL) & 168 & $(30)$ & 181 & $(43)$ & 171 & $(36)$ & 187 & $(39)$ & 0.03 \\
\hline Serum creatinine $(\mathrm{mg} / \mathrm{dL})$ & 1.0 & $(0.1)$ & 1.0 & $(0.2)$ & 1.0 & $(0.2)$ & 1.0 & $(0.2)$ & 0.09 \\
\hline Godin score of leisurely activity & 53.1 & $(32)$ & 50.7 & $(34)$ & 59.1 & $(32)$ & 43.5 & $(32)$ & 0.08 \\
\hline $\begin{array}{l}\text { Estimated glomerular filtration } \\
\text { rate (MDRD) } \mathrm{mL} / \mathrm{min} / 1.73 \mathrm{~m}^{2}\end{array}$ & 94 & $(17)$ & 90 & $(13)$ & 93 & (18) & 90 & $(14)$ & 0.06 \\
\hline
\end{tabular}

All summary statistics presented are mean \pm (standard deviation) unless specified other-wise. ${ }^{*}$ Age, sex, and race adjusted trend tested by ordinary least squares regression unless otherwise specified; ${ }^{* *}$ only adjusted for race and sex.

Table 2. Carotid artery measures of study subjects by the stratum of serum uric acid: cross sectional analyses of baseline data ( $\mathrm{n}=189$ ).

\begin{tabular}{|c|c|c|c|c|c|}
\hline $\begin{array}{l}\text { Carotid artery measure ( } \mathrm{mm} \text { unless indicated otherwise) } \\
\text { Men } \\
\text { Women } \\
\text { Carotid lumen diameters }\end{array}$ & $\begin{array}{c}\text { Quartile } 1 \\
<4.9 \\
<3.6\end{array}$ & $\begin{array}{c}\text { Ur } \\
\text { Quartile } 2 \\
4.9-5.6 \\
3.6-4.2\end{array}$ & $\begin{array}{l}\text { id } \\
\text { Quartile } 3 \\
5.7-6.2 \\
4.2-4.6\end{array}$ & $\begin{array}{c}\text { Quartile } 4 \\
>6.2 \\
>4.6\end{array}$ & $\begin{array}{l}\text { P value } \\
\text { for trend* }\end{array}$ \\
\hline Average lumen diameter during diastole & $5.5(0.6)$ & $5.4(0.4)$ & $5.6(0.5)$ & $5.6(0.6$ & $<0.001$ \\
\hline Adventitial diameter & $6.7(0.1)$ & $6.0(0.1)$ & $6.9(0.5)$ & $6.9(0.6)$ & $<0.001$ \\
\hline Intima media thickness & $6.2(0.1)$ & $6.0(0.1)$ & $6.3(0.1)$ & $6.3(0.1)$ & 0.48 \\
\hline Percent change in lumen diameter from diastole- to systole (\%) & $13(4)$ & $12(4)$ & $12(3)$ & $12(3)$ & 0.51 \\
\hline Carotid-femoral average pulse wave velocity (cm/second) & $461(59)$ & $489(110)$ & $498(78)$ & $483(129)$ & 0.51 \\
\hline Pressure strain modulus $(\mathrm{kPa})$ & $69(25)$ & $77(31)$ & $73(28)$ & $78(35)$ & 0.37 \\
\hline
\end{tabular}

*By using ordinary least squares regression; uric acid concentration as a continuous variable

Table 3. Multivariable regression coefficients ( \pm standard error) for each quartile increase in serum uric acid adjusted for age, gender, race (white, non-white), serum creatinine, systolic blood pressure, current alcohol use, body mass index and current smoking by ordinary least squares regression. The lowest quartile was the comparator group.

\begin{tabular}{|c|c|c|c|c|c|}
\hline \multirow{2}{*}{$\begin{array}{l}\text { Carotid artery measure } \\
\text { Men } \\
\text { Women }\end{array}$} & \multicolumn{4}{|c|}{ Uric acid } & \multirow[b]{2}{*}{$\begin{array}{l}\text { P value } \\
\text { comparing } \\
\text { highest to }\end{array}$} \\
\hline & $\begin{array}{l}\text { Quartile } 1 \\
<4.9 \\
<3.6\end{array}$ & $\begin{array}{c}\text { Quartile } 2 \\
4.9-5.6 \\
3.6-4.2\end{array}$ & $\begin{array}{c}\text { Quartile } 3 \\
5.7-6.2 \\
4.2-4.6\end{array}$ & $\begin{array}{l}\text { Quartile } 4 \\
>6.2 \\
>4.6\end{array}$ & \\
\hline Average lumen diameter during diastole (mm) & - & $-0.03(0.11)$ & $0.25(0.11)$ & $0.24(0.11)$ & 0.04 \\
\hline Percent change in lumen diameter (\%) & - & $-1.1(0.79)$ & $-2.2(0.01)$ & $-2.2(0.84)$ & 0.01 \\
\hline End-diastolic adventitial diameter (mm) & - & $0.03(0.11)$ & $0.27(0.11)$ & $0.24(0.12)$ & 0.04 \\
\hline Intima media thickness (mm) & - & $0.008(0.013)$ & $-0.006(0.013)$ & $-0.003(0.014)$ & 0.82 \\
\hline Carotid-femoral average pulse wave velocity (cm/second) & - & $36(20)$ & $-2(22)$ & $-0.2(22)$ & 0.99 \\
\hline Pressure strain modulus (kPa) & - & $10(7)$ & $13(7)$ & $11(7)$ & 0.14 \\
\hline
\end{tabular}


Specifically, early atherosclerosis is manifested by dilatation of carotid artery, and this in turn is associated with plaque progression over time. ${ }^{24}$ In this report we present, for the first time, evidence for a pathophysiological step that can explain the observed epidemiological link between hyperuricemia and hypertension.,25 Individuals with hyperuricemia had wider carotid arteries that were less able to stretch during the cardiac cycle in response to the pressure wave, indicating a decreased compliance of the carotid artery. Such changes are indicative of vascular remodeling, a response to vascular damage, ${ }^{26}$ and are also consistent with premature aging among those with hyperuricemia. ${ }^{27}$

The lack of associations between uric acid and the arterial stiffness measures, aPWV and pressure strain modulus, could be due to the fact that these measures have more inherent error involved in their collection. This error can arise from the technician measured distances between carotid and femoral sites for the aPWV measurement, and from the variability of brachial artery blood pressure in the pressure strain modulus measurement. An alternative explanation could be that the carotid dilation seen in this young study population is very early on in the process of arteriosclerosis, such that it does not yet correspond to a level of arterial stiffening that is large enough to pick up with global stiffness measures. The most prominent factor for arterial stiffness is age: with increasing age, arteries become stiffer equally for men and women. With increasing age, the orderly structure of the elastic laminae is disturbed due to thinning and fracture of the elastic laminae, alterations that appear to be more pronounced in the central arteries than in the peripheral arteries. ${ }^{28}$ It is likely that the young adults in this study have yet to experience significant structural changes in either central or peripheral arteries.

The increased carotid diameters seen in this study are instead likely caused by functional changes, perhaps due in part to the increased oxidative stress and impaired nitric oxide production that occur with hyperuricemia.. ${ }^{29-31}$ Another possible mechanism might be inflammation. ${ }^{32-37}$

\section{Conclusions}

Limitations of this study include the crosssectional design and relatively small size that precluded detection of smaller changes in pulse wave velocity. Measurement of vascular reactivity, if performed would have permitted a better documentation of the effect of hyperuricemia on vessel wall dynamics. Adiposity is a major determinant of several of the vascular measurements that we performed. The use of body mass index as a metric for adiposity is imprecise; however, re-analyses using waist circumference as the adiposity metric did not change the results.

While our observations have established an association between wider arterial diameters and hyperuricemia, much more work remains to be done. Prior studies have hinted at a beneficial effect of urate lowering: ${ }^{37-39}$ these need to be confirmed and extended to all urate lowering treatments. The relative significance of inhibition of XO compared to the purely uricosuric effect of probenecid remains a matter of great interest, as yet un-assessed in prospective studies.

\section{References}

1. Fang J, Alderman MH. Serum uric acid and cardiovascular mortality the NHANES I epidemiologic follow-up study, 1971-1992. National Health and Nutrition Examination Survey. JAMA 2000;283:2404-10.

2. Johnson RJ, Kang DH, Feig D, et al. Is there a pathogenetic role for uric acid in hypertension and cardiovascular and renal disease? Hypertension 2003;41:1183-90.

3. Baker JF, Krishnan E, Chen L, Schumacher HR. Serum uric acid and cardiovascular disease: recent developments, and where do they leave us? Am J Med 2005118:81626.

4. Krishnan E, Kwoh CK, Schumacher HR, Kuller L. Hyperuricemia and incidence of hypertension among men without metabolic syndrome. Hypertension 2007;49: 298-303.

5. Yamamoto $\mathrm{Y}$, Ogino $\mathrm{K}$, Igawa $\mathrm{G}$, et al. Allopurinol reduces neointimal hyperplasia in the carotid artery ligation model in spontaneously hypertensive rats. Hypertens Res 2006;29:915-21.

6. Wannamethee SG, Shaper AG, Whincup $\mathrm{PH}$. Serum urate and the risk of major coronary heart disease events. Heart 1997;78:147-53.

7. Kawamoto R, Tomita H, Oka Y, Ohtsuka N. Relationship between serum uric acid concentration, metabolic syndrome and carotid atherosclerosis. Intern Med 2006; 45:605-14.

8. Ishizaka N, Ishizaka Y, Toda E, et al. Higher serum uric acid is associated with increased arterial stiffness in Japanese individuals. Atherosclerosis 2007;192:1317.

9. Iribarren C, Folsom AR, Eckfeldt JH, et al. Correlates of uric acid and its association with asymptomatic carotid atherosclerosis: the ARIC Study. Atherosclerosis risk in communities. Ann Epidemiol 1996;6:331-
40.

10. Crouse JR, Toole JF, McKinney WM, et al. Risk factors for extracranial carotid artery atherosclerosis. Stroke 1987;18:990-6.

11. Viazzi F, Parodi D, Leoncini G, et al. Serum uric acid and target organ damage in primary hypertension. Hypertension 2005;45: 991-6.

12. Grundy SM, Cleeman JI, Daniels SR, et al. Diagnosis and management of the metabolic syndrome: an american heart association/national heart, lung, and blood institute scientific statement. Circulation 2005;112:2735-52.

13. Godin G, Shephard RJ. A simple method to assess exercise behavior in the community. Can J Appl Sport Sci 1985;10:141-6.

14. Rule AD, Larson TS, Bergstralh EJ, et al. Using serum creatinine to estimate glomerular filtration rate: accuracy in good health and in chronic kidney disease. Ann Intern Med 2004;141:929-37.

15. Sutton-Tyrrell K, Newman A, Simonsick EM, et al. Aortic stiffness is associated with visceral adiposity in older adults enrolled in the study of health, aging, and body composition. Hypertension 2001;38: 429-33.

16. Sutton-Tyrrell K, Wolfson SK Jr, Thompson T, Kelsey SF. Measurement variability in duplex scan assessment of carotid atherosclerosis. Stroke 1992;23:215-20.

17. Wildman RP, Mackey RH, Bostom A, et al. Measures of obesity are associated with vascular stiffness in young and older adults. Hypertension 2003;42:468-73.

18. Nagai Y, Fleg JL, Kemper MK, et al. Carotid arterial stiffness as a surrogate for aortic stiffness: relationship between carotid artery pressure-strain elastic modulus and aortic pulse wave velocity. Ultrasound Med Biol 1999;25:181-8.

19. Crouse JR, Goldbourt U, Evans G, et al. Risk factors and segment-specific carotid arterial enlargement in the Atherosclerosis Risk in Communities (ARIC) cohort. Stroke 1996;27:69-75.

20. Jensen-Urstad K, Jensen-Urstad M, Johansson J. Carotid artery diameter correlates with risk factors for cardiovascular disease in a population of 55 -year-old subjects. Stroke 1999;30:1572-6.

21. Ruan L, Chen W, Srinivasan SR, et al. Correlates of common carotid artery lumen diameter in black and white younger adults: the Bogalusa Heart Study. Stroke 2009;40:702-7.

22. Eigenbrodt ML, Sukhija R, Rose KM, et al. Common carotid artery wall thickness and external diameter as predictors of prevalent and incident cardiac events in a large population study. Cardiovasc Ultrasound 2007;5:11.

23. Bots ML, Grobbee DE, Hofman A, Witteman JC. Common carotid intima- 
media thickness and risk of acute myocardial infarction: the role of lumen diameter. Stroke 2005;36:762-7.

24. Steinke W, Els T, Hennerici M. Compensatory carotid artery dilatation in early atherosclerosis. Circulation 1994;89: 2578-81.

25. Krishnan E, Baker JF, Furst DE, Schumacher HR. Gout and the risk of acute myocardial infarction. Arthritis Rheum 2006;54:2688-96.

26. Lakatta EG. Arterial and cardiac aging: major shareholders in cardiovascular disease enterprises: Part III: cellular and molecular clues to heart and arterial aging. Circulation 2003;107:490-7.

27. Schott LL, Kao AH, Cunningham A, et al. Do carotid artery diameters manifest early evidence of atherosclerosis in women with rheumatoid arthritis? J Womens Health (Larchmt) 2009;18:21-9.

28. Bots ML, Dijk JM, Oren A, Grobbee DE. Carotid intima-media thickness, arterial stiffness and risk of cardiovascular disease: current evidence. J Hypertens 2002; 20:2317-25.

29. Lee YJ, Chang DM, Tsai JC. Association of a 27-bp repeat polymorphism in intron 4 of endothelial constitutive nitric oxide synthase gene with serum uric acid levels in Chinese subjects with type 2 diabetes. Metabolism 2003;52:1448-53.

30. Leyva F, Anker S, Swan JW, et al. Serum uric acid as an index of impaired oxidative metabolism in chronic heart failure. Eur Heart J 1997;18:858-65.

31. Johnson RJ, Rodriguez-Iturbe B, Kang DH, et al. A unifying pathway for essential hypertension. Am J Hypertens 2005;18: 431-40.

32. Coutinho Tde A, Turner ST, Peyser PA, et al. Associations of serum uric acid with markers of inflammation, metabolic syndrome, and subclinical coronary atherosclerosis. Am J Hypertens 2007;20:83-9.

33. Kanellis J, Watanabe S, Li JH, et al. Uric acid stimulates monocyte chemoattractant protein-1 production in vascular smooth muscle cells via mitogen-activated protein kinase and cyclooxygenase-2. Hypertension 2003;41:1287-93.

34. Ruggiero C, Cherubini A, Ble A, et al. Uric acid and inflammatory markers. Eur Heart J 2006;27:1174-81.
35. Leyva F, Anker SD, Godsland IF, et al. Uric acid in chronic heart failure: a marker of chronic inflammation. Eur Heart J 1998; 19:1814-22.

36. Olexa P, Olexova M, Gonsorcik J, et al. Uric acid - a marker for systemic inflammatory response in patients with congestive heart failure? Wien Klin Wochenschr 2002;114: 211-5.

37. Doehner W, Schoene N, Rauchhaus M, et al. Effects of xanthine oxidase inhibition with allopurinol on endothelial function and peripheral blood flow in hyperuricemic patients with chronic heart failure: results from 2 placebo-controlled studies. Circulation 2002;105:2619-24.

38. Struthers AD, Donnan PT, Lindsay P, et al. Effect of allopurinol on mortality and hospitalisations in chronic heart failure: a retrospective cohort study. Heart 2002;87: 229-34.

39. Hoieggen A, Alderman MH, Kjeldsen SE, et al. The impact of serum uric acid on cardiovascular outcomes in the LIFE study. Kidney Int 2004;65:1041-9. 